\title{
Lymphadenectomy in thoracoscopic surgery
}

Thoracoscopic approach in anatomic pulmonary resection including lobectomy or segmentectomy has been accepted as a useful approach in terms of less invasiveness worldwide, especially for early-staged non-small cell lung cancer $(1,2)$. There have been so many reports describing better perioperative outcomes in thoracoscopic anatomic pulmonary resection than those in thoracotomy approach $(3,4)$. Based on the results, $73 \%$ of pulmonary lobectomy and $82 \%$ of segmentectomy were currently performed via thoracoscopic approach in Japan (5).

Although thoracoscopic approach revealed equivalent prognosis to thoracotomy for early-staged non-small cell lung cancer in several reports, it is still controversial whether it can be oncologically acceptable or not. Especially, validity of lymphadenectomy via thoracoscopic approach is unclear. However, minimally invasive surgery including thoracoscopic approach is currently desired among many patients to ensure postoperative rapid recovery due to the less invasiveness. Therefore, thoracic surgeon should master the equivalent surgical skill of lymphadenectomy via thoracoscopic approach to via thoracotomy approach. To achieve it, we conducted the special series about "lymphadenectomy in thoracoscopic surgery" here.

Recently, thoracoscopic surgery is classified into three types including conventional multiportal or emerging uniportal thoracoscopy, and robotic assist. The best way to perform valid lymphadenectomy is different in each approach because the number of usable surgical instruments, operative maneuverability, or surgical view depends on the approach. In this special series, experts in each approach summarized tips of the lymphadenectomy.

Before the details of lymphadenectomy via each approach, Dr. Toker and colleagues kindly summarized how to evaluate the quality of lymphadenectomy in lung cancer resections. Although there is no obvious data showing that complete removal of the lymph nodes significantly improved the prognosis compared to the sampling, assessment of hilar and mediastinal lymph nodes at the time of surgical resection has been recognized as a key aspect. They reviewed the current guidelines on intrathoracic lymph node assessment for lung cancer resections, examined current practice patterns, reported survival differences with varying levels of lymph node dissection, and propose methods to improve quality of lymphadenectomy. Moreover, they finally insisted that systemic mediastinal lymphadenectomy is recommended in any types of surgical approaches including thoracotomy, thoracoscopy, and robotic assist.

Dr. Matsuura and colleagues described "Thoracoscopic lymphadenectomy via multiportal approach: a narrative review". They insisted that appropriate lymph node dissection like "complete" or "perfect" lymphadenectomy, which was different from lymph node sampling, is oncologically necessary based on the histopathological results that tumor clusters floated in the lymphatic duct. Moreover, they considered that lymphadenectomy in multiportal thoracoscopic approach can ensure equivalent quality with that in thoracotomy approach when a highly experienced surgeon performs it. I totally agree with their opinion. Finally, surgical procedures of lymphadenectomy in each zone described in the report can contribute to better understanding of "perfect" lymphadenectomy for readers.

Dr. Nakazawa and colleagues demonstrated tips and pitfalls when using energy devices during thoracoscopic surgery for the patients with lung cancer. Although an optimal way to perform lymph node dissection in lung cancer surgery remains unclear, the use of energy devices in lymphadenectomy has theoretically several benefits due to the sealing effects, curved rotation tip and ability to decrease complications. While these advantages can reduce the postoperative morbidity rate, thermal damage to surrounding tissues is considered as one of the most careful disadvantages. They advocated that correct dissection with deep understanding of anatomical structures was essential to avoid this complication related with the use of energy devices, showing the schemas of anatomy in right or left upper mediastinum.

Uniportal thoracoscopic approach in major pulmonary resections is an emerging technique worldwide because of the less invasiveness. Although it is becoming easier to perform with gaining the experiences, it has technically difficulties, especially in lymphadenectomy because the number of inserted surgical instruments via a small skin incision is limited. Dr. Al-Qtishat and colleagues explained the specific technique in each station of lymph node with high-quality video to overcome the difficulties, which will be help for readers to perform it safely and appropriately. Moreover, they insisted that subcarinal zone in left side was the most challenging part to perform lymph node dissection appropriately because it was deeply located, compared to other stations. Therefore, we asked Dr. Homma and colleagues to focus on the lymphadenectomy in subcarinal 
zone in addition to the excellent description of it by Dr. Al-Qtishat and colleagues. Dr. Homma and colleagues explained how to proceed the lymphadenectomy appropriately by using the illustrated schemas of subcarinal zone, which was useful not only via uniportal approach but also others including via thoracotomy, multiportal or robotic-assisted approach. Finally, they provided several tips of lymphadenectomy in subcarinal zone via uniportal approach, which included an appropriate port position corresponding to the treated lobe and suitable surgical instruments, based on their abundant experiences of uniportal thoracoscopic lobectomies.

Dr. Gharagozloo described "Mediastinal lymphadenectomy during robotic pulmonary resection". Several authors demonstrated that thoracoscopic lobectomy is superior to thoracotomy in terms of perioperative results including morbidity rate. However, thoracoscopic approach has limitations in maneuverability of surgical instruments with twodimensional visualization. Robotic-assisted approach overcomes these limitations by providing precise surgical instruments maneuverability with three-dimensional visualization. Cautionary point is that surgical steps are different between thoracoscopic and robotic-assisted approaches. In this article, Dr. Gharagozloo demonstrated details of port placements and surgical steps in robotic-assisted approach, which is useful for surgeons to perform lobectomy via this approach safely.

In conclusion, the focused series "Lymphadenectomy in thoracoscopic surgery" is one of the most important topics for treating the patients with lung cancer because appropriate lymphadenectomy can bring adequate pathological staging and may oncologically improve the prognosis. I really appreciate that the six experts kindly contributed to this great work. Finally, I hope that this work can be help for readers to perform appropriate lymphadenectomy via minimally invasive approach.

\section{Acknowledgments}

Funding: None.

\section{Footnote}

Provenance and Peer Review: This article was commissioned by the editorial office, AME Surgical fournal for the series "Lymphadenectomy in Thoracoscopic Surgery". The article did not undergo external peer review.

Conflicts of Interest: All authors have completed the ICMJE uniform disclosure form (available at https://asj.amegroups.com/ article/view/10.21037/asj-22-1/coif). The series "Lymphadenectomy in Thoracoscopic Surgery" was commissioned by the editorial office without any funding or sponsorship. HI served as the unpaid Guest Editor of the series and serves as an unpaid editorial board member of AME Surgical fournal from April 2021 to March 2023. The authors have no other conflicts of interest to declare.

Ethical Statement: The authors are accountable for all aspects of the work in ensuring that questions related to the accuracy or integrity of any part of the work are appropriately investigated and resolved.

Open Access Statement: This is an Open Access article distributed in accordance with the Creative Commons AttributionNonCommercial-NoDerivs 4.0 International License (CC BY-NC-ND 4.0), which permits the non-commercial replication and distribution of the article with the strict proviso that no changes or edits are made and the original work is properly cited (including links to both the formal publication through the relevant DOI and the license). See: https://creativecommons.org/licenses/by-nc$\mathrm{nd} / 4.0 /$.

\section{References}

1. Kirby TJ, Mack MJ, Landreneau RJ, et al. Lobectomy--video-assisted thoracic surgery versus muscle-sparing thoracotomy. A randomized trial. J Thorac Cardiovasc Surg 1995;109:997-1001; discussion 1001-2.

2. Sugi K, Kaneda Y, Esato K. Video-assisted thoracoscopic lobectomy achieves a satisfactory long-term prognosis in patients with clinical stage IA lung cancer. World J Surg 2000;24:27-30; discussion 30-1. 
3. Long H, Tan Q, Luo Q, et al. Thoracoscopic surgery versus thoracotomy for lung cancer: short-term outcomes of a randomized trial. Ann Thorac Surg 2018;105:386-92.

4. Wang Z, Pang L, Tang J, et al. Video-assisted thoracoscopic surgery versus muscle-sparing thoracotomy for non-small cell lung cancer: a systematic review and meta-analysis. BMC Surg 2019;19:144.

5. Committee for Scientific Affairs, The Japanese Association for Thoracic Surgery; Shimizu H, Okada M, et al. Thoracic and cardiovascular surgeries in Japan during 2018: Annual report by the Japanese Association for Thoracic Surgery. Gen Thorac Cardiovasc Surg 2021;69:179-212.

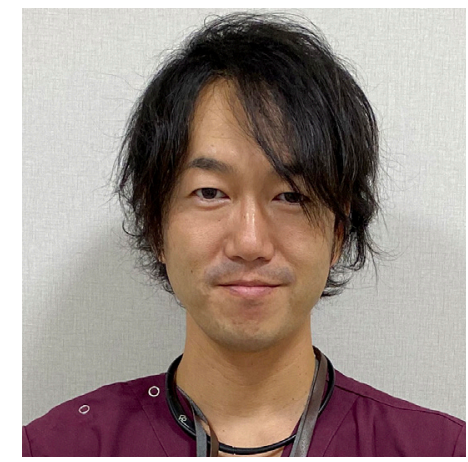

Hitoshi Igai

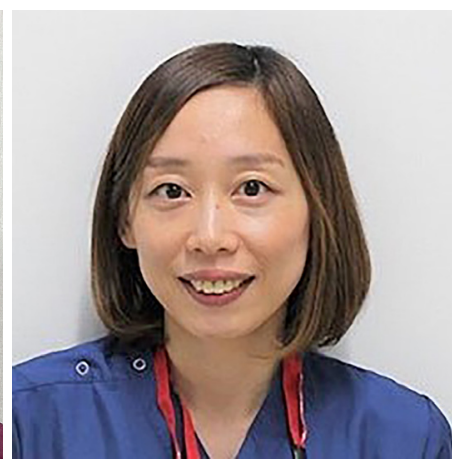

Natsumi Matsuura

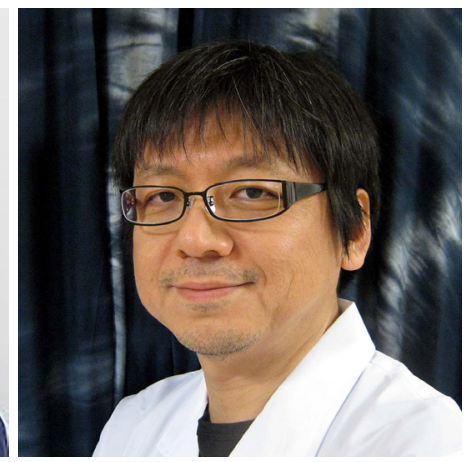

Mitsuhiro Kamiyoshihara

Hitoshi Igai, $\mathrm{MD}, \mathrm{PhD}$

(Email: bitoshiigai@gmail.com) Natsumi Matsuura, MD, PhD

(Email: nmori1130@gmail.com)

Mitsuhiro Kamiyoshihara, MD, PhD

(Email:micha2005jp@yahoo.co.jp)

Department of General Thoracic Surgery, Fapanese Red Cross Maebashi Hospital, Maebashi, Japan.

Received: 03 January 2022; Accepted: 17 January 2022; Published: 30 March 2022.

doi: $10.21037 /$ asj-22-1

View this article at: https://dx.doi.org/10.21037/asj-22-1

doi: $10.21037 /$ asj-22-1

Cite this article as: Igai H, Matsuura N, Kamiyoshihara M. Lymphadenectomy in thoracoscopic surgery. AME Surg J 2022;2:1. 